九州大学学術情報リポジトリ

Kyushu University Institutional Repository

\title{
Space Plasma Environment
}

Hada, Tohru

Faculty of Engineering Sciences, Kyushu University : Professor

https://doi.org/10.15017/1960655

出版情報: Proceedings of International Exchange and Innovation Conference on Engineering \& Sciences (IEICES). 4, pp. 14-15, 2018-10-18. 九州大学大学院総合理工学府 バージョン：

権利関係 : 


\section{Keynote Speakers}

\section{Tohru Hada}

Professor, Faculty of Engineering Sciences

Kyushu University, Japan

Email:hada@esst.kyushu-u.ac.jp

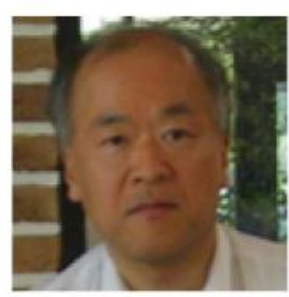

\section{Short Biography}

Tohru Hada is Professor of Interdisciplinary Graduate School of Engineering Sciences (IGSES) at Kyushu University. Upon graduation from the University of Tokyo with his M. Sc. degree in Geophysics in 1981, he went to the U.S.A. on Fulbright fellowship to continue his study and received his $\mathrm{Ph}$. D. degree in Physics from University of California at Los Angeles (UCLA) in 1985. He then worked as a post-doctoral research fellow at the Department of Physics and also at the Institute of Geophysics and Planetary Physics, UCLA. His work at UCLA was focused on the theoretical and numerical analysis of nonlinear plasma waves, in particular, large amplitude magnetohydrodynamic (MHD) waves and turbulence in space plasmas. In 1989 he returned to Japan and joined the College of General Education at Kyushu University as an Associate Professor. He then moved to the Faculty of Engineering before joining the IGSES in 1998. At Kyushu University, he has been working on multiple areas relevant to space and astrophysical environments, including collisionless shock waves in space, acceleration and transport of cosmic rays, nonlinear plasma waves and solitons, development of novel techniques for analyzing spacecraft data, modeling of nextgeneration plasma thrusters, and numerical and data analysis research on space weather. He served as a director of the International Center for Space Weather Science and Education (ICSWSE), Kyushu University, from 2012 to 2018. 


\title{
Space Plasma Environment
}

\begin{abstract}
It is not only the atmosphere and the ocean that constitute the Earth's environment. Once you leave the Earth and travel into space, you will find that space is not a vacuum as is often misunderstood, but is filled with a medium called plasma, an extremely high-temperature gas that conducts electricity. Via this plasma, the Earth's environment is linked to outer space, in particular, to the dynamic activities of the sun. In this talk, I will first introduce some of the basic concepts related to the space plasma, e.g., the solar wind, the magnetosphere, and the collisionless shock waves. Then I will introduce the cosmic rays, i.e., energetic charged particles of space origin, and discuss how they are accelerated to extremely high energies and how they travel in space. In particular, I will show how the cosmic rays are efficiently accelerated by the collisionless shock waves.
\end{abstract}

